\title{
Polygonatum sibiricum polysaccharide affects growth performance and immune response in cyclophosphamide-induced immunosuppressed chickens
}

\section{Dan Xu}

Sichuan Agricultural University

Jin Zhao

sichuan agricultural university

Chonglin Ran

sichuan agricultural university

Lu Xu

sichuan agricultural university

Shaojun Ren

sichuan agricaltural university

Yuanlin Huang

sichuan agricultural university

Ziting Tang

sichuan agricultural university

Juchun Lin

sichuan agricultural university

Hualin Fu

sichuan agricaltural university

Wei Zhang

sichuan agricultural university

Changliang He

sichuan agricultural university

Xiaoling Zhao

sichuan agricultural unversity

Gang Shu ( $\nabla$ dyysg2005@sicau.edu.cn )

Sichuan Agricultural University

Research article 
Keywords: Broilers; Blood indices; Diet; Growth; Immunity; Pharmacology

Posted Date: September 25th, 2019

DOI: https://doi.org/10.21203/rs.2.14956/v1

License: (c) (1) This work is licensed under a Creative Commons Attribution 4.0 International License. Read Full License 


\section{Abstract}

Background: This study aims to identify the effects of dietary Polygonatum sibiricum polysaccharide (PP) on growth performance and blood parameters in immunosuppressed chickens induced by cyclophosphamide (CY). Results: The results showed that PP enhanced the growth performance and immune response in chickens treated with cyclophosphamide characterized by increasing relative weight of thymus, total antioxidant capacity (T-AOC), superoxidase dismutase (SOD), albumin (ALB), immunoglobulin $M(\operatorname{lgM})$, and antibody titers of Newcastle disease (ND) and avian influenza (H9), and decreasing feed conversion ratio (FCR) and malondialdehyde (MDA) level. Conclusions: PP enhanced chickens' growth performance via improving antioxidant ability and alleviating $\mathrm{CY}$-induced immunological stress.

\section{Background}

Infectious diseases and mycotoxins induce immunosuppression, a disorder of immune system in broilers, which reduces immune response to vaccines, increases morbidity and mortality of flocks $[1,2]$ and causes higher feed conversions and lower average daily weight gains $[3,4]$.

Cyclophosphamide (CY) is an alkylating agent widely used to build immunosuppression and stress animal models via intramuscular $[5,6]$ or intraperitoneal injection. It inhibited both humoral and cellular immunity, causing B cell damage irreversibly [5] and depressed both antibody formation and immunoglobulin synthesis [7]. Strategies to minimize immunosuppressed diseases are mainly via vaccination and stress control [2]. However, inactivated vaccine cannot produce sufficient antibody, attenuated vaccine induces reactivation and infection [8]. Therefore, new methods to control stress are in great demand.

Polygonatum sibiricum polysaccharide (PP) is a recently isolated water soluble component of rhizome polygonatum, which has medicinal efficiency in enhancing immune function [9], vital essence replenishment, dryness removal, and promotion of fluid secretion . In laboratory animals, PP has the potential as a treatment of diabetes and ocular complications, an alternative to estrogen to treat osteoporosis, a neuroprotective agent, a prevention for osteoporosis, and a remedy for inflammatory disorders [10-13]. Liu had shown that the polysaccharide from Polygonatum sibiricum played an important role in the protection of the Cy-treated immunosuppressed mice and could be used as a potential immunostimulant agent [14]. However, its protective effect against immunosuppression in chickens is poorly understood. Therefore, the objective of the present study was to elucidate the effects of PP on growth performance, immune and biochemical traits of immunosuppressed chickens induced by $\mathrm{CY}$.

\section{Results}

\section{Growth Performance}


Growth performance indices were affected by $\mathrm{CY}$ and PP during the overall period. From $\mathrm{d} 21$ to $\mathrm{d} 28$, $\mathrm{PP}+\mathrm{CY}$ group had lower DFI and FCR compared with $\mathrm{CY}$ group $(p<0.05)$. CY group had lower DFI and DWG from $\mathrm{d} 1$ to $\mathrm{d} 35$ compared with the Control $(p<0.05)$ (Table 1$)$.

\section{Serum Antioxidant Indices}

PP group had the highest T-AOC and SOD and the lowest MDA among all groups at all time points. CY group had the lowest T-AOC and SOD, and the highest MDA at all time points, compared with other groups. $\mathrm{PP}+\mathrm{CY}$ had lower MDA compared with $\mathrm{CY}$ group on d 14 and $21(p<0.05)($ Table 2$)$.

\section{Blood Biochemical Indices}

PP group had higher TP $(p<0.05)$ than $\mathrm{CY}$ and PP+CY groups on $\mathrm{d} 14$. CY group had lower ALB than other groups on d $14(p<0.05)$. PP group had higher ALB compared with other groups on $\mathrm{d} 28(p<0.05)$ (Table 2).

\section{Immune Organ Relative Weights}

For spleen, $\mathrm{PP}$ groups were higher than $\mathrm{CY}$ and $\mathrm{PP}+\mathrm{CY}$ groups on $\mathrm{d} 14$ and $28(p<0.05)$. For relative weights of thymus, the Control and PP groups were higher than $\mathrm{CY}$ and $\mathrm{PP}+\mathrm{CY}$ on $\mathrm{d} 14(p<0.05)$. PP+CY group was higher than $\mathrm{CY}$ group on d $21(p<0.05)$. For bursa, the Control and PP groups were higher than $\mathrm{CY}$ and PP+CY groups on $\mathrm{d} 14,21$, and $28(p<0.05)$ (Table 3$)$.

\section{Effect of PP on Immunoglobulin}

IgG levels had no difference among four groups. For IgM, the Control was the lowest on d $14(p<0.05)$. PP group was higher than $\mathrm{CY}$ and PP+CY group on $\mathrm{d} 28(p<0.05)$ (Table 4$)$.

\section{Effect of PP on Antibody Assay}

For ND, CY group was the lowest on $\mathrm{d} 14(p<0.05)$. $\mathrm{PP}+\mathrm{CY}$ group was higher than $\mathrm{CY}$ at all time points $(p<0.05)$. The Control was higher than $\mathrm{CY}$ at all time points $(p<0.05)$. For $\mathrm{H} 9, \mathrm{CY}$ was lower than $\mathrm{PP}$ and $\mathrm{PP}+\mathrm{CY}$ on $\mathrm{d} 14(p<0.05)$. CY group was the lowest on $\mathrm{d} 21(p<0.05)$. PP was the highest and $\mathrm{CY}$ group was the lowest compared to other treatments on d $28(p<0.05)$ (Table 5).

\section{Discussion}

In the present study, we built the model of immunosuppression chickens induced by CY in order to study PP's function in growth promoting and immune booster in broilers. The results indicated that the growth performance, relative weights of bursa, Spleen and thymus, antibody titers to ND and H9 of CY group decreased $(p<0.05)$ compared to the Control, which were consistent with the immunosuppressed model in other studies with bursa atrophy that showed depression of ND and $\mathrm{HI}$ antibody production [15]. 
Studies have indicated that the deficiency of immune system resulted in poor growth performance, low DFI and DWG and high FCR [16]. Consistent with this finding, CY lowered DWG and DFI from d 1 to $d 35$ compared to Control group in our study $(p<0.05)$. However, PP group had higher DWG and DFI from $d 1$ to d 35 and lower FCR from d 7 to $d 21$ compared with PP+CY group $(p<0.05)$, which indicated that PP displayed positive effect on chicken growth and promoted the feed conversion efficiency of birds. In consistent with other studies, Astragalus polysaccharide, and $2 \mathrm{~g} / \mathrm{kg}$ polysaccharide extracts of Lentinus edodes inclusion increased broilers' BWG and decreased FCR $[17,18]$.

T-AOC is an integrate and sensitive antioxidant index that identifies oxidative status in vivo [19]. MDA is the product of lipid peroxidation and tissue damage manifestation [20]. CY caused overproduction of reactive oxygen species (ROS) [21], which is an inclusion of superoxide anion $\left(\mathrm{O}_{2}{ }^{-}\right)$, hydroxyl radical ( $\left.\mathrm{OH}\right)$, and hydrogen peroxide $\left(\mathrm{H}_{2} \mathrm{O}_{2}\right)$. ROS cause damage of nuclear acids, proteins and lipids [22]. SOD catalyzes $\mathrm{O}_{2}{ }^{-}$to $\mathrm{O}_{2}$, produces $\mathrm{H}_{2} \mathrm{O}_{2}$, and maintains body within a low superoxide concentration. According to the reduction in T-AOC on d 14 and d 21, and SOD on d 14 in PP+CY group compared with PP group, administration of $\mathrm{CY}$ in chickens induced oxidative stress in the present study. $\mathrm{PP}+\mathrm{CY}$ group decreased MDA on $\mathrm{d} 14$ and $21(p<0.05)$ compared to $\mathrm{CY}$ group, indicating PP restored oxidative effect of $\mathrm{CY}$, which is in consistent with former studies. Polysaccharides extracted from Platycodon grandiflorum [23], Rhododendron aganniphum [24], Pleurotus eryngii [25] , and Glycine soja [26] have great antioxidant capacity in elevating SOD and decreasing MDA concentration in pheochromocytoma cells and showing good radical scavenging activity for 1,1-diphenyl-2-picrylhydrazyl radicals in vitro.

Serum biochemical parameters reflect nutritional status in broilers [27]. Serum total protein contains albumin and globulin, reflecting protein anabolism, immune status [28], and hepatic protein metabolic status [29]. Elevation of ALB reflects increased antioxidant, immunomodulatory, and detoxification functions [30]. The TP concentration on $\mathrm{d} 14$ in PP group was higher compared with $\mathrm{PP}+\mathrm{CY}$ group ( $p$ $<0.05)$ and PP group had the highest ALB, compared with other groups on $d 28(p<0.05)$, which was in consistent with increased antioxidant status and improved growth performance in PP groups in this study. The mechanism of PP on protein synthesis or catabolism to improve protein anabolism needs to be further investigated.

Immune responses of broilers were evaluated by assessing immune organ relative weights, concentrations of IgG and IgM, and antibody titers of ND and $\mathrm{H} 9$ in the current study. CY intramuscular administration decreased relative weights of thymus on $\mathrm{d} 14$ and 21 , bursa on $\mathrm{d} 14,21$, and $28(p<0.05)$ compared to the Control, which are in line with previous studies [31] . However, PP+CY increased relative weights of thymus on d 21 compared to CY group, PP group had higher relative weights of spleen on $\mathrm{d} 14$ and 28 and bursa during the whole period compared with PP+CY group, indicating that PP could resist the immunosuppression on development of immune organs induced by $\mathrm{CY}$. Previous studies proved the positive effect of polysaccharides' immune on spleen $[17,32]$ and relative weights of thymus and bursa [1] . 
IgG is the principle antibody in immune response for anti-infection, and IgM arises in initial stage of antiinfection immune response [2]. The levels of IgG and IgM are indicators of antiviral response capacity [33]. In the current study, PP group had higher IgM on d 28 than PP+CY group and on $d 21$ than Control group $(p<0.05)$, which indicated that PP enhances anti-infection and anti-virus ability of chickens. Similar results have been reported in previous studies. Polysaccharides extracted from Astragalus membranaceu, Astragalus, sulfated epimedium, Tremella fuciformis, and Lentinus edodes increased production of $\lg G$ and $\lg M$ in chickens [34].

Antibody titers manifest humoral immune response mediated by $\mathrm{B}$ lymphocyte. The results showed $\mathrm{PP}+\mathrm{CY}$ had higher antibody titer of ND and $\mathrm{H} 9$ compared with $\mathrm{CY}$ group during the whole period $(p<0.05)$. This indicates that PP resisted the decreased antibody formation and immunoglobulin synthesis induced by $\mathrm{CY}$, which confirms immunomodulatory effects of polysaccharides. Polysaccharide from Epimedium polysaccharide-propolis flavone, Astragalus, sulfated epimedium, and achyranthan had higher anti-ND titers $(p<0.05)$ than the control in chickens $[1,2]$.

\section{Conclusions}

PP at a dose of $800 \mathrm{mg} / \mathrm{kg}$ in diets enhanced immune response in a local meat-type chicken induced by $\mathrm{CY}$ and improved its growth performance and antioxidant levels. PP may be a potential feed additive to mount a successful defense against immunodeficiency diseases in chickens and other animals as well.

\section{Methods}

\section{Reagents and Viruses}

Polygonatum sibiricum polysaccharide (content>99\%) was purchased from Zhejiang Shengshi Biotechnology Co. Ltd (Zhejiang, P. R. China).

Cyclophosphamide with the purity of $83.84 \%$ was purchased from Jiangsu Hengrui Medicine Co. Ltd (Jiangsu, P. R. China). The chicken-specific ELISA assay kits for total antioxidant capacity (T-AOC), malondialdehyde (MDA), superoxidase dismutase (SOD), total protein (TP), albumin (ALB), Immunoglobulin G (IgG), and Immunoglobulin M (IgM) were purchased from Nanjing Jiancheng Bioengineering Institute (Nanjing, P. R. China). Avian influenza (H9 subtype) and Newcastle disease (ND) virus were purchased from Wens Dahuanong Biotechnology Co. Ltd (Guangdong, P. R. China).

\section{Animals Husbandry and Immunosuppressed Model Design}

The objective of the present study was to elucidate the effects of PP on growth performance, immune and biochemical traits of immunosuppressed chickens induced by $\mathrm{CY}$.

Four hundred and eighty one-day-old Erlang mountainous chickens (line SD02) were provided by Poultry Breeding Farm of Sichuan Agricultural University and had free access to water and basal diets which met 
the NRC requirements [35]. And the formulation and nutrient levels were according to the National Research Council and shown in Table 6.Chickens were raised in cages in a ventilated house maintained at $50 \%$ relative humidity. The photoperiod was $24 \mathrm{~h}$ for the first 14 days and $20 \mathrm{~h}$ for the subsequent days. Temperature was $34^{\circ} \mathrm{C}$ initially and decreased by $2^{\circ} \mathrm{C}$ per week to $24^{\circ} \mathrm{C}$, which was maintained till the end of the experiment.

Polygonatum sibiricum polysaccharide at 0 or $800 \mathrm{mg} / \mathrm{kg}$ of the diet and $\mathrm{CY}$ at 0 or $80 \mathrm{mg} / \mathrm{kg}$ were used in a $2 \times 2$ factorial designed with 4 randomized complete blocks consisting of initial BW of $37.83 \pm 3.45 \mathrm{~g}$ chickens. They were allocated into 4 groups: 1$)$ non $\mathrm{CY}$-induced control (CON; birds fed basal diets and treated with sterile saline); 2) CY-induced control (CY; birds fed basal diets and treated with $80 \mathrm{mg} / \mathrm{kg}$ $\mathrm{CY}$ ); 3) non CY-induced group + PP (PP; birds fed basal diets supplemented with $800 \mathrm{mg} / \mathrm{kg}$ PP and treated with sterile saline); 4) CY-induced group + PP (PP + CY; birds fed basal diets supplemented with $800 \mathrm{mg} / \mathrm{kg}$ PP and treated $80 \mathrm{mg} / \mathrm{kg} \mathrm{CY}$ ). There were four replicates (30 birds per replicate) randomly assigned into each of 4 diet groups. $\mathrm{CY}$ and sterile saline were delivered through intramuscular injection on $\mathrm{d} 7,8$, and 9 , respectively with a dose of $80 \mathrm{mg} / \mathrm{kg}$ of body weight according to the previous report. Our previous study showed basal diet supplemented with $800 \mathrm{mg} / \mathrm{kg}$ PP had better effect than 200 $\mathrm{mg} / \mathrm{kg}, 400 \mathrm{mg} / \mathrm{kg}$, and $1200 \mathrm{mg} / \mathrm{kg}$ on increasing daily weight gain (DWG), daily feed intake (DFI), relative weights of bursa, spleen, thymus and SOD, TP, ALB, T-AOC, and decreasing feed conversion ratio (FCR) and MDA.

\section{Growth Performance}

Feed intake was monitored for each cage every week after a $12 \mathrm{~h}$ fast. Average DWG and DFI were weighed on $\mathrm{d} 1,7,14,21,28$, and 35 . FCR was calculated as DWG/DFI. These growth performance parameters were adjusted by mortality. On $\mathrm{d} 14,21$, and 28 , five chickens close to mean body weight were euthanized by injecting pentobarbital sodium intravenously at a dose of $100 \mathrm{mg} / \mathrm{kg}$ without any fear and agony, as pentobarbital sodium can inhabit the ascending reticular activating system of brainstem, leading to the death of animals. And tissues were collected and stored at $-80^{\circ} \mathrm{C}$ for further analysis.

\section{Biochemical Parameter Assay}

On $\mathrm{d} 14,21$, and $28,1 \mathrm{~mL}$ of blood was obtained from the brachial vein and centrifuged at $2,000 \mathrm{xg}$ for $5 \mathrm{~min}$. Supernatant liquid of blood serum was collected and stored at $-20^{\circ} \mathrm{C}$ for further analysis. The contents of T-AOC, SOD, MDA, TP, and ALB were measured using ELISA kits according to manufacturer's instructions.

\section{Immune Organ Relative Weight}

Spleen, thymus, and bursa were collected and weighed on d 14, 21, and 28. Immune organ relative weights were expressed as the ratio of organ weight to body weight $(\mathrm{mg} / \mathrm{g})$.

\section{Serum Immunoglobulin and Antibody Assays}


Blood samples of $2.0 \mathrm{~mL}$ were extracted from the main brachial vein of chicken and clotted at $37^{\circ} \mathrm{C}$ for 2

h. To collect serum, the blood samples were centrifuged at 2,000 $\mathrm{xg}$ for $3 \mathrm{~min}$. IgG and IgM were measured using ELISA kits according to manufacturer's instructions. The serum antibody titers of subtype avian influenza viruses H9 (H9) and Newcastle disease virus (ND) were assessed by hemagglutination assay $(\mathrm{HA})$ and hemagglutination inhibition $(\mathrm{HI})$ assay. The concentrations of titer were recorded as $\log _{2}$ value. The reciprocal of the highest dilution was the complete agglutination.

\section{Statistical Analysis}

Data were analyzed by one-way analysis of variance (ANOVA) via SPSS 19.0. software. Duncan's multiple range test was used to determine the differences among groups. Significance was assigned at $p<0.05$.

\section{Abbreviations}

PP: Polygonatum sibiricum polysaccharide, CY : cyclophosphamide, T-AOC: total antioxidant capacity, SOD: superoxidase dismutase, ALB: albumin, IgM: immunoglobulin M, IgG: Immunoglobulin G, ND: antibody titers of Newcastle disease, H9: avian influenza, FCR: decreasing feed conversion ratio, MDA: malondialdehyde, TP: total protein, CON: control, DWG : daily weight gain, DFI : daily feed intake , HI: hemagglutination inhibition, HA: hemagglutination

\section{Declarations}

\section{Ethics approval and consent to participate}

All procedures for raising and slaughtering chickens were performed according to the Guide for the Care and Use of Laboratory Animals of the Chinese Association for Laboratory Animal Sciences and approved by the Institutional Animal Care and Use Committee of Sichuan Agricultural University with an issued number DYY-S20130538.

\section{Consent for publication}

Not applicable.

\section{Availability of data and materials}

The datasets used and/or analysed during the current study are available from the corresponding author on reasonable request.

\section{Competing interests}

The authors declare that they have no competing interests.

\section{Funding}


This work was supported by the [National Natural Science Foundation of China] under Grant [number 31402070], and the funder conceived and designed the experiments, also purchased all the test consumables.

\section{Authors' contributions}

SG, ZJ and ZXI conceived and designed the experiments. XD, XL, RSj and ZW performed the experiments. $\mathrm{SG}, \mathrm{XD}, \mathrm{RCl}$ and $\mathrm{HCl}$ finished the Draft of the manuscript. HYI, TZt, LJC and FHI analyzed the data. All authors had read and approved the manuscript.

\section{Acknowledgements}

We deeply appreciate that Paul B. Siegel gave professional comments on this manuscript, which greatly improved the paper quality.

\section{References}

[1] Chen HL, Li DF, Chang BY, Gong LM, Dai JG and Yi GF. Effects of Chinese herbal polysaccharides on the immunity and growth performance of young broilers. Poultry Science 2003; 82: 364.

[2] Fussell LW. Poultry industry strategies for control of immunosuppressive diseases. Poultry Science 1998; 77: 1193.

[3] Hoerr FJ. Clinical Aspects of Immunosuppression in Poultry. Avian Diseases 2010; 54: 2-15.

[4] Gabal MA and Azzam AH. Interaction of aflatoxin in the feed and immunization against selected infectious diseases in poultry. II. Effect on one-day-old layer chicks simultaneously vaccinated against Newcastle disease, infectious bronchitis and infectious bursal disease. Avian Pathology 1998; 27: 290295.

[5] El-Abasy M, Motobu M, Nakamura K, Koge K, Onodera T, Vainio O, Toivanen P and Hirota Y. Preventive and therapeutic effects of sugar cane extract on cyclophosphamide-induced immunosuppression in chickens. International Immunopharmacology 2004; 4: 983-990.

[6] Furthermore, Levamisole SA, telerones, Lfucose A and As AW. Immunomodulatory Effects of Kuseonwangdogo-Based Mixed Herbal Formula Extracts on a Cyclophosphamide-Induced Immunosuppression Mouse Model. Evidence-Based Complementray and Alternative Medicine,2018, (2018-4-8) 2018; 2018: 1-14.

[7] Shaojin Z, Bingling L, Xiao L, Lei L, Libao M and Xianghua Y. Effects of yeast cell walls on performance and immune responses of cyclosporine A-treated, immunosuppressed broiler chickens. British Journal of Nutrition 2012; 107: 858-866. 
[8] Dou W, Li H, Cheng Z, Zhao P, Liu J, Cui Z, Liu H, Jing W and Guo H. Maternal antibody induced by recombinant gp85 protein vaccine adjuvanted with CpG-ODN protects against ALV-J early infection in chickens. Vaccine 2013; 31: 6144-6149.

[9] Peng X, He J, Zhao J, Wu Y, Shi X, Du L, Nong M, Zong S and Zeng GF. Polygonatum sibiricum polysaccharide promotes osteoblastic differentiation through the ERK/GSK-3 $\beta / \beta$-catenin signaling pathway in vitro. Rejuvenation Research 2017; rej.2017.1956.

[10] Zeng G, Zhang Z, Lu L, Xiao D, Xiong C, Zhao Y and Zong S. Protective effects of Polygonatum sibiricum polysaccharide on ovariectomy-induced bone loss in rats. Journal of Ethnopharmacology 2011; 136: 0-229.

[11] Haroon K, Muhammad S, Malik Hassan M, Najeeb-Ur R, Naveed M, Ikram-Ul H, Nadeem A, El-Tahir $\mathrm{KEH}$ and Anwarul-Hassan G. Studies on tracheorelaxant and anti-inflammatory activities of rhizomes of Polygonatum verticillatum. BMC Complementary and Alternative Medicine,13,1(2013-07-29) 2013; 13: 18.

[12] Zhang H, Cao Y, Chen L, Wang J, Tian Q, Wang N, Liu Z, Li J, Wang N and Wang X. A polysaccharide from Polygonatum sibiricum attenuates amyloid- $\beta$-induced neurotoxicity in PC12 cells. Carbohydrate Polymers 2015; 117: 879-886.

[13] Wang Y, Qin S, Pen G, Chen D, Han C, Miao C, Lu B, Su C, Feng S and Li W. Original Research: Potential ocular protection and dynamic observation of Polygonatum sibiricum polysaccharide against streptozocin-induced diabetic rats' model. Experimental Biology \& Medicine 2017; 242: 92-101.

[14] Liu N, Dong Z, Zhu X, Xu H and Zhao Z. Characterization and protective effect of Polygonatum sibiricum polysaccharide against cyclophosphamide-induced immunosuppression in Balb/c mice. International Journal of Biological Macromolecules 2017; 107: S0141813016309941.

[15] Okoye JO, Nwosuh Cl, Onwujiobi CB, Onuoha AS and Okonkwo PU. Pathogenesis of infectious bursal disease in cyclophosphamide-treated chickens. Avian Pathology 1992; 21: 615-620.

[16] Xi H, Yang $X$ and Guo Y. Effects of different dietary oil sources on immune function in cyclophosphamide immunosuppressed chickens. Animal Feed Science \& Technology 2007; 139: 186200.

[17] Wang X, Li Y, Shen J, Wang S, Yao J and Yang X. Effect of Astragalus polysaccharide and its sulfated derivative on growth performance and immune condition of lipopolysaccharide-treated broilers. International Journal of Biological Macromolecules 2015; 76: 188-194.

[18] Luo JY. Effects of mushroom and herb polysaccharides, as alternatives for an antibiotic, on growth performance of broilers. British Poultry Science 2004; 45: 684-694. 
[19] Ghiselli A, Serafini M, Natella F and Scaccini C. Total antioxidant capacity as a tool to assess redox status: critical view and experimental data. Free Radical Biol Med 2000; 29: 1106-1114.

[20] Haribabu, Reddy, Seshadri V, Pallavi, Bitla, Aparna R, Pullaiah, Rao and Srinivasa PVLN. Evaluation of protein oxidation and its association with lipid;peroxidation and thyrotropin levels in overt and subclinical;hypothyroidism. Endocrine 2013; 44: 152-157.

[21] Jeelani R, Khan SN, Shaeib F, Kohan-Ghadr HR, Aldhaheri SR, Najafi T, Thakur M, Morris R and AbuSoud HM. Cyclophosphamide and acrolein induced oxidative stress leading to deterioration of metaphase II mouse oocyte quality. Free Radical Biology \& Medicine 2017; 110: 11-18.

[22] Yu J, Chen Y, Zhai L, Zhang L, Xu Y, Wang S and Hu S. Antioxidative effect of ginseng stem-leaf saponins on oxidative stress induced by cyclophosphamide in chickens. Poultry Science 2015; 94: 927933.

[23] Sheng Y, Liu G, Wang M, Lv Z and Du P. A selenium polysaccharide from Platycodon grandiflorum rescues $\mathrm{PC} 12$ cell death caused by $\mathrm{H} 2 \mathrm{O} 2$ via inhibiting oxidative stress. International Journal of Biological Macromolecules 2017; 104: 393-399.

[24] Xiao G, Shang X, Zhou X, Zhao B and Zhang J. Ultrasound-assisted extraction of polysaccharides from Rhododendron aganniphum: Antioxidant activity and rheological properties. Ultrasonics Sonochemistry 2017; 38: 246-255.

[25] Jia X, Wang C, Bai Y, Yu J and Xu C. Sulfation of the Extracellular Polysaccharide Produced by the King Oyster Culinary-Medicinal Mushroom, Pleurotus eryngii (Agaricomycetes), and Its Antioxidant Properties In Vitro. International Journal of Medicinal Mushrooms 2017; 19: 355-362.

[26] Jing C, Yuan Y, Tang Q, Zou P, Li Y and Zhang C. Extraction optimization, preliminary characterization and antioxidant activities of polysaccharides from Glycine soja. International Journal of Biological Macromolecules

[27] Gao CQ, Yang JX, Chen MX, Yan HC and Wang XQ. Growth curves and age-related changes in carcass characteristics, organs, serum parameters, and intestinal transporter gene expression in domestic pigeon (Columba livia). Poultry Science 2016; 95: 867.

[28] Li XJ, Piao XS, Kim SW, Liu P, ., Wang L, ., Shen YB, Jung SC and Lee HS. Effects of chitooligosaccharide supplementation on performance, nutrient digestibility, and serum composition in broiler chickens. Poult Sci 2007; 86: 1107-1114.

[29] Stoll B, ., Burrin DG, Henry J, ., Yu H, ., Jahoor F, . and Reeds PJ. Dietary amino acids are the preferential source of hepatic protein synthesis in piglets. Journal of Nutrition 1998; 128: 1517-1524.

[30] Rita GM, Paolo C, Mauro B, Pere G, Vicente A and Rajiv J. Albumin: pathophysiologic basis of its role in the treatment of cirrhosis and its complications. Hepatology 2013; 58: 1836-1846. 
[31] Yunpeng F, Yu L, Deyun W, Jiaguo L, Xiaoping S, Weimin Z, Xiaojuan Z, The Luong N and Yuanliang $\mathrm{H}$. Effect of epimedium polysaccharide-propolis flavone immunopotentiator on immunosuppression induced by cyclophosphamide in chickens. Cellular Immunology 2013; 281: 37-43.

[32] Liu L, Shen J, Zhao C, Wang X, Yao J, Gong Y and Yang X. Dietary Astragalus polysaccharide alleviated immunological stress in broilers exposed to lipopolysaccharide. International Journal of Biological Macromolecules 2015; 72: 624-632.

[33] Herr M, Bostedt $\mathrm{H}$ and Failing K. IgG and IgM levels in dairy cows during the periparturient period. Theriogenology 2011; 75: 377-385.

[34] Guo L, Liu J, Hu Y, Wang D, Li Z, Zhang J, Qin T, Liu X, Liu C and Zhao X. Astragalus polysaccharide and sulfated epimedium polysaccharide synergistically resist the immunosuppression. Carbohydrate Polymers 2012; 90: 1055-1060.

[35] Leeson S. Nutrient requirements of poultry. 1977.

\section{Tables}

Table 1 Effect of Polygonatum sibiricum polysaccharide on growth performance in chickens (Mean $\pm \mathrm{SE}$ )

\begin{tabular}{cccccccc}
\hline Item & Age $(\mathrm{d})$ & \multicolumn{2}{c}{$0 \mathrm{~g}$ of PP } & \multicolumn{2}{c}{$800 \mathrm{mg} / \mathrm{kg}$ PP } & SEM & $p$-value \\
\cline { 3 - 6 } & & Saline & CY & Saline & CY & & \\
\hline DFI & $1-7$ & 6.40 & 6.34 & 6.37 & 6.32 & 0.035 & 0.427 \\
& $7-14$ & $17.61^{\mathrm{a}}$ & $15.70^{\mathrm{bc}}$ & $16.52^{\mathrm{b}}$ & $15.45^{\mathrm{c}}$ & 0.250 & 0.000 \\
& $14-21$ & $29.42^{\mathrm{a}}$ & $27.17^{\mathrm{b}}$ & $28.86^{\mathrm{a}}$ & $27.04^{\mathrm{b}}$ & 0.438 & 0.002 \\
& $21-28$ & $43.71^{\mathrm{a}}$ & $42.36^{\mathrm{a}}$ & $42.04^{\mathrm{a}}$ & $40.25^{\mathrm{b}}$ & 0.466 & 0.011 \\
& $28-35$ & $49.85^{\mathrm{a}}$ & $46.55^{\mathrm{a}}$ & $49.21^{\mathrm{a}}$ & $42.75^{\mathrm{b}}$ & 1.054 & 0.002 \\
& $1-35$ & $29.19^{\mathrm{a}}$ & $27.69^{\mathrm{bc}}$ & $28.31^{\mathrm{ab}}$ & $26.36^{\mathrm{c}}$ & 0.357 & 0.008 \\
DWG & $1-7$ & 2.48 & 2.44 & 2.67 & 2.54 & 0.083 & 0.299 \\
& $7-14$ & $9.47^{\mathrm{a}}$ & $6.67^{\mathrm{b}}$ & $9.14^{\mathrm{a}}$ & $6.87^{\mathrm{b}}$ & 0.203 & 0.000 \\
& $14-21$ & $17.40^{\mathrm{a}}$ & $13.81^{\mathrm{b}}$ & $17.02^{\mathrm{a}}$ & $13.49^{\mathrm{b}}$ & 0.332 & 0.000 \\
& $21-28$ & 20.35 & 20.18 & 21.36 & 20.83 & 0.271 & 0.061 \\
& $28-35$ & $23.53^{\mathrm{a}}$ & $20.51^{\mathrm{b}}$ & $22.64^{\mathrm{a}}$ & $19.58^{\mathrm{b}}$ & 0.630 & 0.002 \\
& $1-35$ & $14.71^{\mathrm{a}}$ & $13.05^{\mathrm{b}}$ & $14.62^{\mathrm{a}}$ & $12.65^{\mathrm{b}}$ & 0.187 & 0.000 \\
& $1-7$ & 2.59 & 2.62 & 2.40 & 2.49 & 0.086 & 0.303 \\
& $7-14$ & $1.87^{\mathrm{b}}$ & $2.36^{\mathrm{a}}$ & $1.83^{\mathrm{b}}$ & $2.26^{\mathrm{a}}$ & 0.064 & 0.000 \\
& $14-21$ & $1.69^{\mathrm{b}}$ & $1.98^{\mathrm{a}}$ & $1.72^{\mathrm{b}}$ & $2.02^{\mathrm{a}}$ & 0.055 & 0.001 \\
& $21-28$ & $2.12^{\mathrm{a}}$ & $2.10^{\mathrm{a}}$ & $1.97^{\mathrm{b}}$ & $1.94^{\mathrm{b}}$ & 0.030 & 0.030 \\
& $28-35$ & 2.12 & 2.29 & 2.18 & 2.19 & 0.072 & 0.483 \\
& $1-35$ & 1.99 & 2.12 & 1.94 & 2.09 & 0.038 & 0.057 \\
\hline
\end{tabular}

DFI: daily feed intake (g); DWG: daily weight gain (g); FCR: feed conversion ratio; SEM: pooled standard error of the means $(n=4)$.

a-c Means in a row without the same superscripts differ significantly $(\mathrm{p}<0.05)$ 
Table 2 Effect of dietary PP on serum biochemical indices of chickens (Mean \pm SE)

\begin{tabular}{|c|c|c|c|c|c|c|}
\hline \multirow[t]{2}{*}{ Item } & \multicolumn{2}{|c|}{$0 \mathrm{~g} \mathrm{PP}$} & \multicolumn{2}{|c|}{800 mg/kg PP } & \multirow[t]{2}{*}{ SEM } & \multirow[t]{2}{*}{$p$-value } \\
\hline & Saline & $\mathrm{CY}$ & Saline & CY & & \\
\hline \multicolumn{7}{|c|}{ T-AOC (U/mL) } \\
\hline d 14 & $9.81^{\mathrm{b}}$ & $6.71^{\mathrm{c}}$ & $11.41^{\mathrm{a}}$ & $7.53^{\mathrm{c}}$ & 0.448 & 0.000 \\
\hline d 21 & $8.36^{b}$ & $6.10^{\mathrm{c}}$ & $11.32^{\mathrm{a}}$ & $7.32^{\mathrm{bc}}$ & 0.593 & 0.000 \\
\hline $\mathrm{d} 28$ & $9.83^{\mathrm{ab}}$ & $7.51^{\mathrm{C}}$ & $11.67^{\mathrm{a}}$ & $9.47^{\mathrm{bc}}$ & 0.648 & 0.004 \\
\hline \multicolumn{7}{|c|}{$\mathrm{SOD}(\mathrm{U} / \mathrm{mL})$} \\
\hline d 14 & $173.24^{\mathrm{a}}$ & $113.02^{\mathrm{b}}$ & $190.34^{\mathrm{a}}$ & $124.01^{\mathrm{b}}$ & 10.95 & 0.001 \\
\hline d 21 & 145.93 & 123.45 & 167.77 & 130.91 & 11.62 & 0.103 \\
\hline d 28 & 307.07 & 291.13 & 315.39 & 302.14 & 8.38 & 0.262 \\
\hline \multicolumn{7}{|c|}{$\operatorname{MDA}(\mathrm{mmol} / \mathrm{mL})$} \\
\hline d 14 & $1.65^{\mathrm{b}}$ & $2.25^{\mathrm{a}}$ & $1.43^{\mathrm{b}}$ & $1.69^{\mathrm{b}}$ & 0.134 & 0.013 \\
\hline $\mathrm{d} 21$ & $0.79^{c}$ & $2.19^{\mathrm{a}}$ & $0.60^{\mathrm{c}}$ & $1.49^{b}$ & 0.111 & 0.000 \\
\hline d 28 & 1.19 & 2.06 & 1.06 & 1.56 & 0.099 & 0.001 \\
\hline \multicolumn{7}{|c|}{$\mathrm{TP}(\mathrm{g} / \mathrm{L})$} \\
\hline d 14 & $37.81^{\mathrm{ab}}$ & $33.57^{\mathrm{b}}$ & $42.33^{\mathrm{a}}$ & $34.82^{\mathrm{b}}$ & 1.426 & 0.028 \\
\hline d 21 & 30.27 & 35.58 & 35.26 & 33.30 & 1.364 & 0.253 \\
\hline d 28 & 31.22 & 31.96 & 31.80 & 29.21 & 2.101 & 0.878 \\
\hline \multicolumn{7}{|c|}{ ALB $(g / L)$} \\
\hline d 14 & $16.00^{\mathrm{a}}$ & $13.12^{\mathrm{b}}$ & $15.76^{\mathrm{a}}$ & $15.89^{\mathrm{a}}$ & 0.623 & 0.024 \\
\hline $\mathrm{d} 21$ & 16.64 & 17.38 & 15.57 & 16.47 & 1.147 & 0.766 \\
\hline d 28 & $12.34^{\mathrm{b}}$ & $14.51^{\mathrm{b}}$ & $17.96^{\mathrm{a}}$ & $11.85^{\mathrm{b}}$ & 1.007 & 0.002 \\
\hline
\end{tabular}

T-AOC: total antioxidant capacity (U/mL); MDA: malondialdehyde (mmol/L); SOD: superoxidase dismutase $(\mathrm{U} / \mathrm{mL})$; TP: total protein ( $\mathrm{g} / \mathrm{L})$; ALB: albumin ( $\mathrm{g} / \mathrm{L})$; SEM: pooled standard error of the means $(\mathrm{n}=4)$.

${ }^{\mathrm{a}-\mathrm{c}}$ Means in a row without the same superscripts differ significantly $(p<0.05)$.

Table 3 Effect of PP on relative weights of spleen, thymus, and bursa of chickens (Mean \pm SE) 


\begin{tabular}{cccccccc}
\hline Relative weight & \multicolumn{2}{c}{$0 \mathrm{~g}$ PP } & \multicolumn{3}{c}{$800 \mathrm{mg} / \mathrm{kg}$ PP } & SEM & $p$-value \\
\cline { 2 - 6 } (\% of body weight) & Saline & CY & Saline & CY & & \\
\hline Spleen & $1.49^{\mathrm{ab}}$ & $1.02^{\mathrm{b}}$ & $1.91^{\mathrm{a}}$ & $1.02^{\mathrm{b}}$ & 0.153 & 0.001 \\
d 14 & 1.30 & 1.33 & 1.40 & 1.24 & 0.090 & 0.659 \\
d 21 & $1.84^{\mathrm{ab}}$ & $1.48^{\mathrm{b}}$ & $2.20^{\mathrm{a}}$ & $1.52^{\mathrm{b}}$ & 0.132 & 0.003 \\
d 28 & & & & & & \\
Thymus & $4.38^{\mathrm{a}}$ & $2.03^{\mathrm{b}}$ & $4.56^{\mathrm{a}}$ & $2.04^{\mathrm{b}}$ & 0.365 & 0.000 \\
d 14 & $5.76^{\mathrm{a}}$ & $4.21^{\mathrm{b}}$ & $5.94^{\mathrm{a}}$ & $6.40^{\mathrm{a}}$ & 0.416 & 0.003 \\
d 21 & 6.59 & 6.37 & 7.08 & 6.69 & 0.374 & 0.601 \\
d 28 & & & & & & \\
Bursa & $2.39^{\mathrm{a}}$ & $1.10^{\mathrm{b}}$ & $2.70^{\mathrm{a}}$ & $1.28^{\mathrm{b}}$ & 0.209 & 0.000 \\
d 14 & $4.14^{\mathrm{a}}$ & $1.09^{\mathrm{b}}$ & $3.92^{\mathrm{a}}$ & $1.32^{\mathrm{b}}$ & 0.202 & 0.000 \\
d 21 & $4.94^{\mathrm{a}}$ & $1.28^{\mathrm{b}}$ & $5.02^{\mathrm{a}}$ & $1.68^{\mathrm{b}}$ & 0.224 & 0.000 \\
\hline d 28 & & & & & & \\
\hline
\end{tabular}

SEM: pooled standard error of the means $(n=4)$.

ab Means in a row without the same superscripts differ significantly $(p<0.05)$.

Table 4 Effect of PP on serum globulin of chickens (Mean \pm SE)

\begin{tabular}{ccccccc}
\hline Item & \multicolumn{2}{c}{$0 \mathrm{~g} \mathrm{PP}$} & \multicolumn{2}{c}{$800 \mathrm{mg} / \mathrm{kg} \mathrm{PP}$} & SEM & $p$-value \\
\cline { 2 - 5 } & Saline & CY & Saline & CY & & \\
\hline IgG (g/L) & & & & & & \\
d 14 & 3.22 & 3.66 & 3.34 & 3.66 & 0.211 & 0.401 \\
d 21 & 2.31 & 2.40 & 2.93 & 2.45 & 0.152 & 0.088 \\
d 28 & 2.21 & 1.86 & 2.72 & 2.12 & 0.167 & 0.073 \\
IgM (g/L) & & & & & & \\
d 14 & $1.42^{\mathrm{b}}$ & $1.97^{\mathrm{a}}$ & $2.08^{\mathrm{a}}$ & $1.94^{\mathrm{a}}$ & 0.154 & 0.039 \\
d 21 & 1.51 & 1.83 & 1.60 & 1.65 & 0.106 & 0.248 \\
d 28 & $1.00^{\mathrm{ab}}$ & $1.76^{\mathrm{b}}$ & $2.37^{\mathrm{a}}$ & $1.82^{\mathrm{b}}$ & 0.243 & 0.040 \\
\hline
\end{tabular}

IgG: immunoglobulin G (g/L); IgM: immunoglobulin M (g/L); SEM: pooled standard error of the means $(n=4)$.

${ }^{\mathrm{ab}}$ Means in a row without the same superscripts differ significantly $(p<0.05)$.

Table 5 Effect of PP on serum antibody titer ${ }^{\#}$ of chickens (Mean \pm SE) 


\begin{tabular}{lcccccc}
\hline Item & \multicolumn{2}{c}{0 g PP } & \multicolumn{2}{c}{$800 \mathrm{mg} / \mathrm{kg} \mathrm{PP}$} & SEM & $p$-value \\
\cline { 2 - 5 } & Saline & CY & \multicolumn{2}{c}{ Saline } & CY & \\
\hline ND & & & & & & \\
d 14 & $3.8^{\mathrm{b}}$ & $3.6^{\mathrm{c}}$ & $4.8^{\mathrm{b}}$ & $5.0^{\mathrm{a}}$ & 0.332 & 0.018 \\
d 21 & $3.0^{\mathrm{b}}$ & $2.8^{\mathrm{b}}$ & $4.0^{\mathrm{ab}}$ & $4.2^{\mathrm{a}}$ & 0.284 & 0.009 \\
d 28 & $6.2^{\mathrm{a}}$ & $2.5^{\mathrm{c}}$ & $7.2^{\mathrm{a}}$ & $4.6^{\mathrm{b}}$ & 0.319 & 0.000 \\
H9 & & & & & & \\
d 14 & $4.0^{\mathrm{ab}}$ & $3.6^{\mathrm{b}}$ & $4.8^{\mathrm{a}}$ & $4.8^{\mathrm{a}}$ & 0.245 & 0.006 \\
d 21 & $3.4^{\mathrm{a}}$ & $2.0^{\mathrm{b}}$ & $3.8^{\mathrm{a}}$ & $3.2^{\mathrm{a}}$ & 0.332 & 0.009 \\
d 28 & $5.4^{\mathrm{ab}}$ & $3.0^{\mathrm{c}}$ & $6.0^{\mathrm{a}}$ & $4.8^{\mathrm{b}}$ & 0.329 & 0.000 \\
\hline
\end{tabular}

H9: avian influenza H9 subtype; ND: Newcastle disease; SEM: pooled standard error of the means $(n=4)$.

a-c Means in a row without the same superscripts differ significantly $(p<0.05)$.

\# The antibody titers were shown as $\log _{2}$ value of the reciprocal of the highest dilution.

Table 6 Composition and nutrient levels of the basal diet (air-dry basis) $(\mathrm{g} / \mathrm{kg})$

\begin{tabular}{ccc|ccc}
\hline Ingredients & $1-21 \mathrm{~d}$ & $22-35 \mathrm{~d}$ & Nutrient levels $^{\mathrm{b}}$ & $1-21 \mathrm{~d}$ & $22-35 \mathrm{~d}$ \\
\hline Corn & 565.0 & 621.4 & ME (MJ/kg) & 12.13 & 12.63 \\
Soybean meal & 365.7 & 306.8 & $\mathrm{CP}$ & 205.0 & 182.0 \\
Admixture oil & 28.0 & 32.9 & Lys & 11.50 & 10.10 \\
Limestone CaHPO $_{4}$ & 13.1 & 14.1 & Met + Cys & 8.10 & 7.30 \\
NaCl & 12.6 & 10.9 & $\mathrm{Ca}$ & 9.00 & 8.50 \\
Premix $^{\mathrm{a}}$ & 3.0 & 10.9 & $\mathrm{TP}$ & 5.70 & 5.30 \\
50\% choline (50\%) & 10 & 3.00 & & & \\
Lys & 0.20 & 0.40 & & & \\
Met & 2.4 & 2.2 & & & \\
\hline
\end{tabular}

${ }^{\mathrm{a}}$ The premix provided the following per kg of the diet: Cu 8 mg; Fe 90 mg; Zn 50 mg; Mn 80 mg; I 0.30 mg; Se 0.15 mg; vitamin A(Retinol) $10000 \mathrm{IU}$; vitamin $\mathrm{D}_{3}$ (Cholecalciferol) 2,100 IU冋vitamin E(tocopherol) 14.97 IU; vitamin $\mathrm{K}_{3}$ (menaphthone) $0.6 \mathrm{mg}$; vitamin $\mathrm{B}_{1}$ (thiamine) $2.0 \mathrm{mg}$; vitamin $\mathrm{B}_{2}$ (Riboflavin) 4.0 ng; vitamin $\mathrm{B}_{12}$ (cyanocobalamin) $0.01 \mathrm{mg}$; nicotinic acid $30.0 \mathrm{mg}$; folic acid $0.6 \mathrm{mg}$; biotin $0.15 \mathrm{mg}$; D-pantothenic acid $11 \mathrm{mg}$; phytase $700 \mathrm{U}$.

${ }^{\mathrm{b}}$ Nutrient levels are calculated value.

\section{Supplementary Files}


This is a list of supplementary files associated with this preprint. Click to download.

- ARRIVEchecklist.docx 